\title{
Effect of China's Fiscal Expenditure on Economic Growth
}

\author{
Mengyao Li \\ School of economics and management, Wuhan University, Wuhan, 430072, China
}

\author{
Keywords: Fiscal expenditure, Economic growth, Effect analysis
}

\begin{abstract}
Development and progress of market economy bring wealth and opportunities to the society as well as great challenges. So, most countries start to adopt market regulation and state intervention to maintain sequence and development of economic market. Finance is an important means for state regulation and intervention, can effectively promote economic growth and bring social development. This paper mainly analyzes effect of Chinese fiscal expenditure on economic growth.
\end{abstract}

\section{Introduction}

Fiscal expenditure is actually a means to promote national development. The effect of national fiscal expenditure on national macroeconomic development gradually becomes an important issue in economic field. Favorable market environment is a major precondition of economic development. Impacts of adverse factors on economic development can be reduced to the largest extent only in a stable environment. In current economic environment, only market regulation function cannot well regulate economic conditions. Hence, national strength needs for proper intervention to make up for shortcomings of market regulation as far as possible and facilitate economic development. At present, main economic regulation modes include finance and economy. Fiscal expenditure has direct influence in economic development. Rational fiscal expenditure contributes to national economic development and social stability.

\section{Basic connotation of fiscal expenditure}

Generally, we regard fiscal expenditure as public property expenditure, i.e. utilize services and articles provided by the government to reach actual development needs of economic market. The basic source of funds is fiscal revenue gained by the country, such as tax. Then, such funds are used as fiscal expenditure for public development. In fact, fiscal expenditure is the second part of national financial allocation, but it is not an important part. The country must abide by relevant legal procedures to gain legal fiscal revenue to provide guarantee for national macro-control. Fiscal expenditure can be divided into unpaid appropriation and paid appropriation. Financial fund is allocated to the same-level or subordinate department, which means unpaid appropriation. In fiscal use process, this is the fundamental fiscal use way. During fiscal appropriation for some state-run enterprises, paid appropriation is generally adopted. In such appropriation way, fiscal fund is utilized for turnover. This belongs to loan issuance form. It can rationally serve as increase and setting of fiscal expenditure. Fiscal expenditure management should follow four principles: 1) make ends meet. During fiscal revenue and fiscal expenditure, the two should reach an equilibrium relation. Meanwhile, the two are also mutually restricted. Fiscal revenue should serves as basic reference for fiscal expenditure. Once fiscal expenditure does not comply with fiscal revenue and increases at will, national economic development will be affected. Therefore, fiscal expenditure should be rationally planned according to fiscal revenue to avoid financial deficit. 2) Make overall plans and take all factors into consideration. In national development process, financial construction, administrative construction, military construction and culture construction are involved, but fiscal revenue is definite and limited. So, fiscal revenue should be disposed rationally to make sure each aspect can meet actual needs so as to facilitate economic development balance. In other words, during fiscal expenditure planning, rational overall planning should be conducted. 3) Pursue benefits. During 
fiscal expenditure, expenditure results should be rationally evaluated. Basically, social benefit and economic benefit should be considered to maximize the benefits, scientifically divide fiscal expenditure, carry out fiscal expenditure in combination of unpaid appropriation and paid appropriation and increase financial fund management and supervision force so as to avoid financial fund misuse and promote maximization of economic benefit. The above content summarizes fiscal use of fiscal expenditure.

\section{Effect of fiscal expenditure on economic growth}

\section{To stabilize economic growth}

In economic development process, each economic component has different functions and jointly drives economic development. Each restraining factor interacts. These functions to some extent depend on economic market management. In other words, economic order of market economy is related to each factor in market competitions. Market environment without rules can to some extent restrict economic development and thus leads to market chaos and economic instability. Hence, a powerful regulation way is needed to regulate it, i.e. state macro-control. At present, the country uses macro-control to regulate and control economic market, which has become universal. Such macro-control can effectively balance the relationship between fiscal expenditure and fiscal revenue and monitor market dynamics. Once economic market is out of control or economy is sluggish, state macro-control can be used to regulate fiscal expenditure balance and redeem adverse effect on state economy so as to drive economic development. These problems need to be solved through state macro-control. In this process, state macro-control plays certain regulation role and effectively avoids large economic fluctuation so as to ensure economic growth.

\section{To perfect economic structure}

As social and economic development as well as economic globalization progress, all countries are brought in economic tide. Competitions no longer appear in China, but also appear in international competitions. Besides, cooperation is not only limited to China. Economic development strategy should be reviewed under global perspective. As social progress, traditional economic development mode cannot satisfy social basic needs. Hence, scientific economic development strategy should be continuously established through innovation. This gives rises to certain challenges to traditional economic growth mode. Thus, due to such challenges and opportunities, economic growth mode should be gradually altered. Extensive economic growth mode is not enough. Economic development resulting from such extensive economic growth mode is very unreasonable. It is hard to continue. Environmental benefit and economic growth should be effectively combined to effectively unite them, carry out equal macroeconomic regulation, promote economic growth and develop the two jointly. Economic market can only gain benefit through benefits. Other aspects cannot be fully considered. Therefore, market regulation cannot meet requirements and better development of environmental development factors. Besides, the layout of other industries is not very rational. Hence, national financial regulation is needed. Aiming at the aspect which cannot be met or the part which may be easily ignored, it is necessary to compensate correspondingly by use of fiscal expenditure form to guarantee satisfaction of economic needs and continuously perfect industrial structure so as to reduce the proportion of primary industry in economic development, rationally regulate the secondary industry and positively drive development of the tertiary industry. It is also necessary to gradually change economic structure and meet social development needs. So, certain fiscal expenditure is needed.

\section{To optimize fiscal expenditure and facilitate economic growth}

\section{To improve and enhance financial macro-control}

It is necessary to reasonably expand investment and continuously arrange infrastructure investment force. In general, most funds are used in infrastructure construction, enterprise technology reform, livelihood projects and ecological environment construction. Post-disaster reconstruction 
investment should be rationally used in infrastructure, housing construction and industrial construction in the disaster area to improve input in guarantee-based construction according to actual conditions, such as energy conservation and emission reduction, comfortable housing project and small dangerously weak reservoir reinforcement. For key projects such as civil aviation and railway, it is required to improve government investment mode, rationally arrange construction investment funds of small projects, continuously accumulate and guide construction fund input so as to guarantee stable economic development.

\section{To actively implement fiscal policy}

During use of fiscal expenditure, it is required to properly expand public fund input, carry out structural tax reduction, rationally adjust distribution pattern and gradually become the main content of fiscal management. During implementation of fiscal policy, both tax reduction and investment expansion are needed to better optimize industrial structure, guarantee unification of economic growth and structural adjustment, stimulate consumption and expand investment simultaneously. To rationally improve social benefit of investment and economic effect, some modes which can stimulate social development and drive consumption development should be applied as far as possible. Reasonable adjustment and distribution of national income pattern can effectively improve and promote people's livelihood, increase assistance and subsidy for the group with low income, boost residents' consumption level and consumption power to the largest extent and facilitate economic development.

\section{To improve expenditure budget preparation}

During fiscal expenditure, budget expenditure preparation should be altered continuously to rationally achieve zero-base budget. The core of fiscal expenditure is budget preparation. At present, technical distribution method China is being used can neither meet actual needs nor well reflect specific requirements of unites and each part so as to lead to resource supply-demand contradiction and increase fixed pattern of financial fund allocation. Hence, we need to continuously study new methods, break original modes and achieve zero-base budget, i.e. prepare budget based on zero. In addition, it is also necessary to re-examine fund demand of each department and reallocate funds according to work task and actual conditions of the personnel preparing the budget. In the process of realizing zero-base budget, firstly, it is necessary to check base number, ensure accuracy and authenticity of each base number, prepare the budget through scientific and rational ways and provide guarantee for expenditure budget; secondly, unify budgeting standards and specify standard quota of public fund and personnel to ensure budget fairness and openness; thirdly, rationally standardize preparation program and guarantee legality of zero-base budget; fourthly, it should be very strict to investigate budget preparation, continuously perfect and increase scientificity and normalization of budget preparation. Such budget preparation method can not merely relieve financial contradiction and promote balance of payments, but also boost budget management level and constrain budget. It is required to continuously improve macroeconomic regulation and control ability of national financial sector, optimize financial structure and facilitate economic growth.

\section{To rationally implement centralized national treasury receipt and payment}

Centralized national treasury receipt and payment means all financial funds concentrate to the specified national agency account. As per national provisions, this uniform account allocates funds for all fiscal expenditure. Such way is a universal financial fund management system of national market economy. In current stage, seeing from Chinese development level, to rationally realize centralized national treasury receipt and payment system, an independent account should be established firstly and form national treasury account together with journal. Such way can conveniently unite budget funds, effectively carry out fund account transfer, implement centralized national treasury payment system, establish uniform management system and fund budget system, prepare budget for financial fund and utilize concentrated payment to conduct fiscal appropriation for each unit in a rational way. Such system can effectively promote flexible concentration of treasury payment, uniform allocation and dispatching so as to supervise and manage financial fund expenditure and use, which boosts budget constraining force and fund use efficiency. On the other 
hand, politically, corruption phenomenon can be restrained fundamentally due to disperse financial funds.

\section{To carry out financial purchase system}

Financial purchase system is actually a basic way to select suppliers through open tendering. It is also a system implemented by economic market for financial sector. As social development, implementation of financial purchase system is a management demand under current market environment. Meanwhile, it is also major form of enhancing budget expenditure management, facilitate incorrupt government development and development of pubic property theory. When financial purchase system is implemented, financial purchase scope and scale should be firstly expanded to continuously achieve scale effect. Then, corresponding legal system of financial purchase should be established. Financial purchase should be rationally standardized through correspond laws to enhance supervision effect. Finally, it is required to continuously intensify and manage financial purchase plan, facilitate smooth completion of financial purchase, reduce fiscal expenditure and relieve shortage of funds.

\section{Conclusion}

In one word, regardless of developing countries and developed countries, economic development and growth is the primary task of national development. This is more important especially for developing countries. Market regulation function cannot satisfy social development demand. Thus, national support is needed to promote national economic development.

\section{References}

[1] Guo Jinxiu, Gao Xiwu, Analysis of fiscal expenditure effect based on industrial structure difference. Modern Management Science, 2011(5):68-70.

[2] Han Yuanying, Effect of fiscal expenditure on regional economic growth - empirical study based on Panel Data model. Science Technology and Industry, 2010(6):41-43,59.

[3] Xia Xiangqian, Analysis of economic growth effect of fiscal expenditure structure. Modern Management Science, 2010(11):57-59.

[4] Hu Haixia, Effect of agricultural fiscal expenditure on consumption of rural residents. Huazhong University of Science and Technology, 2011:22.

[5] Zhou Li, Li Degang, Space overflow effect of local fiscal expenditure on total factor productivity -Durbin model based on space panel. Finance \& Economics of Xinjiang, 2014(2):49-57. 